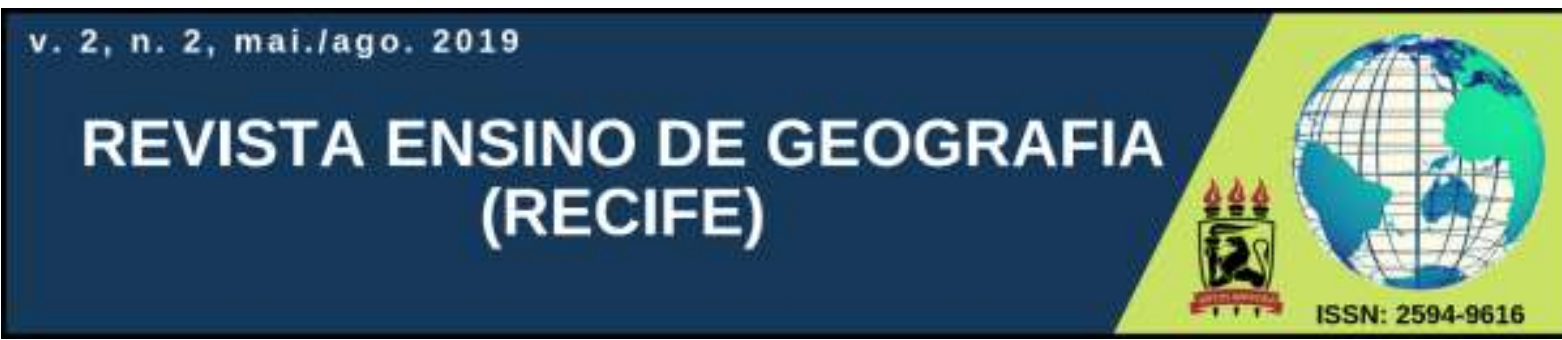

\title{
PAISAGEM NO ENSINO DE GEOGRAFIA URBANA: OLHARES E VIVÊNCIAS NO CENTRO URBANO DO MUNICÍPIO DE IPIAÚ - BAHIA
}

\author{
Patrícia Ferreira Silva \\ Especialista em Ensino de Geografia (UESC) \\ silva.ferreira.patricia@hotmail.com \\ ORCID Id: https://orcid.org/0000-0001-6680-064X \\ Gilmar Alves Trindade \\ Doutor em Geografia (UFS) \\ galvestrindade@gmail.com \\ ORCID iD: https://orcid.org/0000-0002-7547-2120
}

Artigo recebido em 07/08/2019 e aceito em 25/09/2019

\begin{abstract}
RESUMO: As paisagens urbanas são produtos de processos e relações sociais que refletem a cultura e o modo de vida de tal sociedade. Por meio da técnica, a natureza é transformada em objetos culturais expressos e materializada no espaço. A sociedade, como parte integrante da sua produção, cria funções e formas que constituem a organização espacial, com diferentes significados de acordo com as vivências de cada pessoa; esses fatores permitem a construção de conhecimentos globais a partir do lugar onde se vive, e os colocam em conexão com relações socioespaciais cada vez mais complexas. O objetivo deste trabalho é definir possibilidades de análise, leitura e representação da paisagem do centro urbano de Ipiaú-BA, com a identificação de seus principais signos, perspectivas e tendências que estabelecem ferramentas para o estudo da paisagem urbana no ensino de Geografia na educação básica. Teoricamente, o trabalho se apoia nos pressupostos da Geografia Cultural, destacando fundamentos também da Geografia Humanística. A metodologia buscou capturar os signos e elementos culturais presentes na paisagem urbana do Centro de Ipiaú, por meio da descrição e interpretação através de registros fotográficos, pesquisa de campo, além de pesquisa bibliográfica e documental. Os principais signos e elementos culturais identificados na paisagem central urbana de Ipiaú foram: o Cine Éden, a Igreja Matriz de S. Roque, o Edifício St. Paula, o comércio e a Praça Rui Barbosa. A praça se faz presente como lugar onde esses elementos culturais, que são materiais, atuam como signos que estimulam relações imateriais que constroem e modificam o espaço constantemente.
\end{abstract}

Palavras-chave: Espaço Urbano; Geografia Cultural; Geografia Escolar; Paisagem.

\section{LANDSCAPE IN THE TEACHING OF URBAN GEOGRAPHY: LOOKS AND EXPERIENCES IN THE URBAN CENTER OF THE MUNICIPALITY OF IPIAÚ - BAHIA}

\begin{abstract}
Urban landscapes are products of social processes and relationships that reflect the culture and way of life of such a society. Through technique, nature is transformed into expressed cultural objects and materialized in space. Society, as an integral part of its production, creates functions and forms that constitute the spatial organization, with different meanings according to the experiences of each person; these factors allow the construction of global knowledge from the place where one lives, and place them in connection with ever more complex socio-spatial relationships. The objective of this work is to define possibilities of analysis, reading and
\end{abstract}


representation of the landscape of the urban center of Ipiaú-BA, with the identification of its main signs, perspectives and tendencies that establish tools for the study of the urban landscape in the teaching of Geography in basic education. Theoretically, the work is based on the assumptions of Cultural Geography, highlighting also foundations of Humanistic Geography. The methodology sought to capture the signs and cultural elements present in the urban landscape of the Ipiaú Center, through the description and interpretation through photographic records, field research, as well as bibliographical and documentary research. The main signs and cultural elements identified in the central urban landscape of Ipiaú were: the Cine Éden, the Mother Church of S. Roque, the St. Paula Building, the trade and the Rui Barbosa Square. The square is present as a place where these cultural elements, which are material, act as signs that stimulate immaterial relations that constantly construct and modify space.

Keywords: Urban space; Cultural geography; School geography; Landscape.

\section{INTRODUÇÃO}

Segundo Corrêa (2005) a cidade é lugar de ocorrência de processos sociais que se materializam nas funções e formas espaciais, sua distribuição no espaço constitui a organização urbana. Os processos originam formas espaciais mediadas por vários agentes modeladores que ao longo do tempo definem diferentes áreas e localizações, em sua área central as principais atividades comerciais, de serviços e gestão, que tornam o preço do solo nessa área mais elevado.

Esse processo de produção e reprodução da paisagem urbana se concretiza de forma material no espaço e é perceptível através de elementos que fazem parte do cotidiano, como prédios, estabelecimentos comerciais, instituições públicas e privadas, praças etc. Para uma observação da paisagem, segundo Carlos (1999), é necessário analisar dois elementos fundamentais: o material, que é o concreto, a exemplo das construções existentes no espaço; e o imaterial, que são as ações da sociedade guiadas pela cultura sobre o espaço construído. Sendo assim, a observação da paisagem por diferentes sujeitos, leva a uma interpretação individual daquilo que foi construído coletivamente.

Desse modo, a análise da paisagem através da perspectiva da Geografia Cultural exige conhecimento prévio a respeito dos conceitos geográficos e suas aplicações na realidade. Os conceitos são a base para iniciação a uma reflexão geográfica, seja na área física ou humana, refletem a realidade, mas não em sua totalidade; portanto, segundo Trindade (2017, p. 31): “[...] como representação do real que se transforma continuamente, o conceito nos ajuda a compreender, a assimilar a realidade ou um fenômeno qualquer".

Representar o real pode não ser suficiente para a compreensão dos conceitos em sala de aula, pois, com as defasagens existentes na educação, o aluno pode não ter um olhar crítico sobre os elementos presentes na paisagem, mesmo que ela faça parte de seu cotidiano. Sem o estímulo à percepção, as transformações e processos contínuos que modificam a morfologia 
da paisagem podem passar despercebidos. Dessa maneira, Carlos (2004, p. 89) explica que: "[...] o mundo se impõe como efêmero, produto da multiplicação exponencial das coisas materiais e imateriais que afeta nossos sentidos e nossa percepção da realidade”.

Os alunos possuem dificuldade em perceber criticamente a realidade, pois o contexto da educação brasileira, originado de decisões políticas, falha em detectar e solucionar essas deficiências. O professor de Geografia possui a habilidade de guiar o aluno a compreender através do estímulo à percepção da realidade, reconhecendo os processos de produção que culminaram na configuração da paisagem atual; as relações e atores sociais que atuam em diferentes escalas; e a tomar consciência de que o próprio aluno é um agente atuante no espaço.

Antes, o professor precisará ter conhecimento das bases da percepção para, dessa forma, levar os alunos à compreensão de conceitos geográficos que se encontram materializados na composição da paisagem. Somente a percepção levará ao conhecimento objetivo e subjetivo da realidade. A dificuldade em trabalhar a geografia escolar fora das salas de aula é realidade de muitos graduandos em Geografia e professores atuantes. É necessária uma reflexão acerca da ementa das disciplinas que fazem parte do curso de Licenciatura em Geografia, pois, é preciso que a geografia científica e a geografia escolar sejam trabalhadas em conjunto.

Definir propostas metodológicas para o ensino de Geografia Urbana, utilizando-se de elementos presentes na paisagem urbana central de Ipiaú, apoiará o professor de Geografia a levar aos seus alunos uma assimilação, mesmo que de forma simplificada, dos processos que compõem a realidade dos elementos culturais contidos na paisagem urbana. Para isso, é preciso perceber as potencialidades educativas que as cidades possuem e, que além das funções tradicionais de atividades sociais e econômicas, podem exercer o papel de uma escola que forma cidadãos críticos e integra todos os grupos sociais. Portanto, deverá ser destacada as possibilidades em que o espaço urbano central de Ipiaú exerce essa função sociocultural através dos elementos contidos em sua paisagem.

\section{OBJETIVOS}

\section{Objetivo geral}

- Definir possibilidades de análise, leitura e representação da paisagem cultural no espaço urbano de Ipiaú-BA, para o ensino de Geografia Urbana na educação básica. 


\section{Objetivos específicos}

- Discutir as perspectivas e tendências de uso da paisagem - sob a ótica da Geografia Cultural - no estudo do espaço urbano;

- Destacar o espaço urbano e seus elementos socioculturais enquanto contexto espacial para se explorar no ensino de Geografia;

- Identificar os principais signos presentes na paisagem do centro urbano de Ipiaú;

\section{PROCEDIMENTOS METODOLÓGICOS}

\section{Revisão bibliográfica}

Pesquisa bibliográfica em livros e artigos relacionados aos temas: Geografia Cultural, paisagem, espaço urbano e ensino de Geografia, além disso, pesquisa documental e histórica sobre o município de Ipiaú a fim de produzir o embasamento teórico-metodológico necessário para interpretação dos dados empíricos encontrados.

\section{Identificação e caracterização de elementos culturais presentes na paisagem urbana do Centro de Ipiaú.}

O espaço urbano de Ipiaú constitui-se de diversos usos da terra, sendo diferentes formas espaciais coesas porque nelas se executam diferentes atividades que se acham vinculadas ao mesmo processo social; usos que definem áreas como o centro da cidade, local de concentração de comércio, serviços, gestão, de conteúdo social e lazer que atende a uma demanda social além dos próprios habitantes, atraindo cidadãos de municípios vizinhos, essa procura pelo centro de Ipiaú revela sua importância enquanto forma espacial.

\section{Pesquisa de campo}

A pesquisa de campo é ferramenta indispensável para a validação das fundamentações teóricas. Para haver pertinência na confirmação dos fenômenos, o trabalho de campo deve ser organizado de forma que se possa levantar vários dados que incorporem e deem fundamento para os objetivos do estudo. Segundo Latini e Araújo (2009, não paginado): “O trabalho de campo, cuja prática constitui-se numa tradição, é de suma importância para obtenção de 
dados, na substituição dos aspectos teóricos que são vistos no ambiente acadêmico ou escolar pela observação, o que possibilita maior compreensão".

O trabalho de campo na área da ciência geográfica estabelece uma prática crucial, uma vez que, coloca o sujeito em contato com o espaço geográfico e o faz refletir sobre os processos atuantes do passado e do presente que resultaram na configuração atual observada no espaço. Muitos dos conceitos estudados pela Geografia são melhor compreendidos quando inseridos na prática em campo, o que possibilita um estreitamento entre teoria e prática.

\section{REVISÃO BIBLIOGRÁFICA}

Considerar o contexto histórico é fundamental para compreender a morfologia da paisagem urbana. Sendo assim, Carlos (1999, p. 23) diz que: “A paisagem urbana e a cidade nos abrem a perspectiva de entendermos o urbano, a sociedade e a dimensão social e histórica do espaço urbano". Para Carlos (2004), um olhar diferente de análise do espaço urbano sob a perspectiva da Geografia Cultural permite pensar que a própria cidade e a vivência que temos nela podem estimular práticas educativas, no sentido de formar cidadãos críticos e conscientes de seu papel na sociedade. Além disso, permite a construção de conhecimentos globais e nos coloca em conexão com relações socioespaciais cada vez mais complexas, além de apontar a desconstrução do pensamento de cidade como somente palco dos fenômenos.

A Fenomenologia diz respeito à análise da essência dos fatos. Os fatos ou fenômenos estudados não se limitam aos físicos naturais tratados pelas Ciências da Natureza, mas também a reflexões do pensamento, práticas culturais (valores, crenças, artes) e ações humanas (técnicas, vivências). De acordo com Rocha (2003), estes aspectos são a base para a construção, manutenção e reformulação do espaço geográfico.

Os diferentes pensamentos são produto de distintas práticas culturais que guiam as ações humanas no espaço e resultam em sua totalidade na paisagem existente. Este método criado pelo filósofo e matemático alemão, Edmund Husserl (1859-1938), não descarta a objetividade da ciência, apenas "[...] procura trazer o mundo da ciência ao mundo da vida, das experiências humanas, do seu cotidiano". Para Rocha (2003, p. 29), trazer a explicação dos fenômenos para as vivências cotidianas, torna-se de maior compreensão os processos de causa e efeito destes fenômenos no espaço. A apreensão e análise da paisagem urbana, por meio das práticas cotidianas, faz a cidade ganhar significado e sentido.

A Semiótica tem por objeto de estudo todas as linguagens possíveis de serem interpretadas, verbal, que é composta pela linguagem falada ou escrita, gestual, que pode ser 
representada pela língua de sinais e não-verbal que se constitui de símbolos, signos e significados impressos nos fenômenos culturais materiais e imateriais.

Para a análise da paisagem do centro urbano de Ipiaú, a Semiótica servirá como ferramenta para a leitura dos diferentes símbolos e signos presentes, através do estudo dos fatos históricos, sociais, políticos e econômicos que culminaram na existência e organização dos signos no espaço geográfico. Na área central de Ipiaú é possível perceber elementos que possuem uma mensagem pronta para ser interpretada por parte de quem os observa. Cada observador terá uma imagem diferente destes signos, pois em sua leitura há a influência da cultura, contexto que difere de pessoa a pessoa, ou de classe para classe.

De acordo com Rocha (2003, p.36): “[...] a percepção é a forma como, através dos sentidos, as coisas do mundo natural ou humano chegam à consciência”. De modo geral, é a forma como as pessoas se relacionam com o meio. Sendo assim, os elementos que fazem parte da paisagem do centro urbano de Ipiaú, são percebidos de diferentes formas, pois os signos percebidos e seus significados se diferem. Cada sujeito possui uma imagem da cidade, pois, foram internalizadas diferentes formas de sensações que geraram diferentes percepções do que os cerca e, possuindo assim, diferentes significados.

Dentro do amplo campo de discussões do pensamento geográfico, a Geografia Cultural se encontra inserida na área da Geografia Humana. Através desta perspectiva, é possível realizar uma análise dos significados contidos nas paisagens humanas que compõem o espaço urbano, podemos tratar de vários conceitos geográficos, como paisagem, lugar e espaço. No caso desta pesquisa, a paisagem urbana se destaca como objeto de estudo por estar ligada à cultura, pois ela é composta de elementos materiais (construções civis, tecnologias) e não materiais (relações sociais, religiosas e políticas), que são reflexos culturais contidos na paisagem, produto das relações humanas.

Na concepção de Luchiari (2001, p.11): “Em cada época, o imaginário coletivo define a concepção social de natureza e a traduz, transformando-a em artefatos materiais e simbólicos, ou seja, em cultura". Para compreender os elementos culturais contidos nas paisagens urbanas é preciso conhecer os símbolos e seus significados na cultura existente; porém, esse simbolismo, muitas vezes, pode não ser tão aparente. Para Corrêa e Rosendahl (1998), toda paisagem é simbólica e serve ao propósito de reproduzir normas culturais e valores de grupos dominantes, isso porque a paisagem é produto da apropriação e transformação do meio ambiente pelos indivíduos. 
As transformações sofridas na forma e função no centro urbano de Ipiaú, são produto do trabalho da sociedade. Esse processo de produção e reprodução evidencia as necessidades e interesses econômicos e sociais da sociedade e se concretiza de forma material no espaço. De acordo com Luchiari: (2001, p. 12), “As mudanças morfológicas na paisagem não são inócuas e não podem ser analisadas independentemente das práticas sociais. A produção de um novo contexto material altera a forma/paisagem e introduz novas funções, valores e objetos".

\section{RESULTADOS E DISCUSSÕES}

\section{Caracterização do município de Ipiaú-BA}

Antes da chegada dos colonizadores e exploradores, a área que hoje abrange o município era ocupada pela tribo dos Tapuias. No início do século XX, os primeiros exploradores começaram a chegar em busca da extração de madeira, e no lugar da mata começaram a surgir os cacauais e pastagens. Os primeiros arruamentos começaram a surgir, o comércio se expandia e o lugarejo começou a crescer e atrair imigrantes que chegavam em busca de ascensão econômica.

Figura 1: Mapa de localização do município de Ipiaú, sul da Bahia

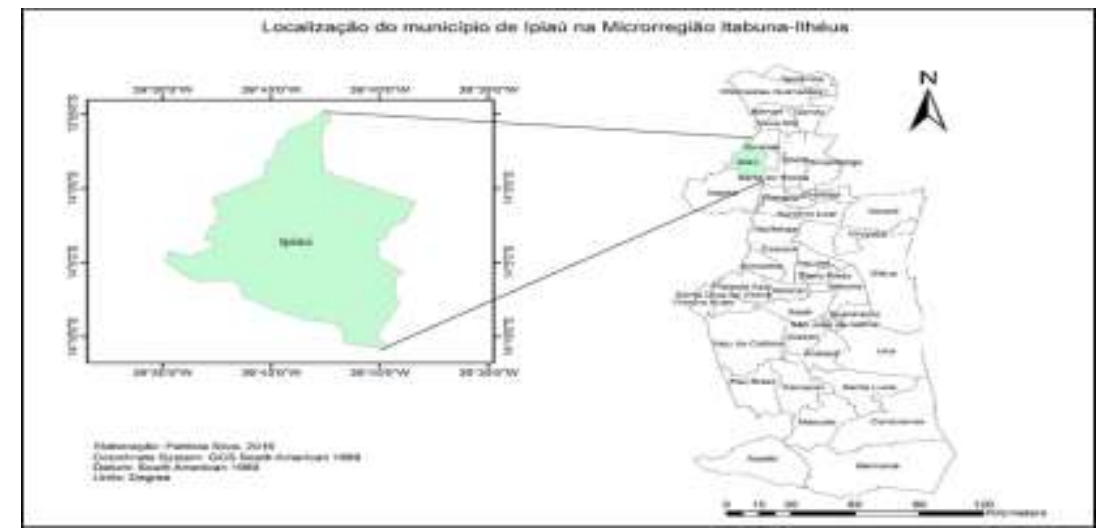

Fonte: Base de dados IBGE, 2016.

A cidade de Ipiaú passou por significativas transformações influenciadas pela produção e cultivo do cacau, principal atividade econômica da região e do município no século XIX. O município transformou-se em um importante centro de zona na hierarquia urbana do Brasil, por exercer influência e atender aos municípios vizinhos na oferta de determinados bens e serviços, o comércio se tornou a principal atividade econômica do município, segundo dados do estudo da Caracterização e Tendências da Rede Urbana do 
Brasil, pesquisa elaborada em 2001, pelo Instituto de Pesquisa Econômica Aplicada (IPEA), Instituto Brasileiro de Geografia e estatística (IBGE) e outros órgãos, com participação da UNICAMP.

De acordo com o histórico do município encontrado na base de dados do IBGE (2008), por volta de 1913 iniciaram-se as primeiras explorações na região para o cultivo do cacau, a excelência do solo, clima e vegetação de Mata Atlântica propiciaram a cultura cacaueira e chamou a atenção de novos exploradores.

Até o ano de 1916 o local não era constituído como cidade, apenas um conjunto de aglomerações ou arruamentos que serviam como referência de localização. A partir desse ano é que o local, distrito de Camamu, foi denominado de Alfredo Martins. Em 1930 foi elevado à categoria de subprefeitura nomeada como Rio Novo. Com a existência de outro município de mesmo nome, em 1943 o nome Rio Novo foi substituído por Ipiaú, que na língua Tupi significa Rio Novo, continuando na categoria de subprefeitura.

Com o desenvolvimento econômico do local veio a necessidade de emancipação e o desmembramento do município de Camamu passando a pertencer ao município de Jequié, localidade que era mais próxima, finalmente em 2 de dezembro de 1933, o distrito é desmembrado de Jequié e elevado à categoria de município.

O município localiza-se no estado da Bahia, mesorregião Sul baiano, na Microrregião Ilhéus-Itabuna (figura 1), segundo IBGE (2008). Limita-se com os municípios de Jequié, Itagibá, Ibirataia, Barra do Rocha, Aiquara e Jitaúna. De clima tropical e vegetação Mata Atlântica, a agricultura do município de Ipiaú é predominada pela lavoura cacaueira e o setor industrial é pouco expressivo, destaca-se como tendência atual para a pecuária e o comércio.

Atualmente, o município é considerado centro de zona de influência por atender aos municípios vizinhos na oferta de determinados bens e serviços. O Produto Interno Bruto (PIB) do município de Ipiaú concentra os maiores valores no setor de serviços, que se tornou a principal atividade econômica do município.

O papel de Ipiaú na rede urbana regional destaca-se como centro de zona, de acordo com a hierarquia urbana, sendo inferior na oferta de bens e serviços em relação aos maiores centros da região, Itabuna e Ilhéus. Sua vocação ocupa lugar específico na rede urbana regional ao estabelecer conexões em menor escala com cidades da mesma rede urbana, mas que se distanciam dos centros maiores. Sua localização na Microrregião Itabuna-Ilhéus limitase com a região de influência de Jequié, essa proximidade pode estabelecer maiores potencialidades ao município, sendo necessário o interesse por parte dos governantes no 
desenvolvimento local. De acordo com análise feita por Trindade (2011, p. 212), “essa estrutura urbana, relativamente complexa se comparada com as pequenas cidades do entorno, por si só, já justificaria a condição de Ipiaú como um centro de zona na região de influência de Itabuna - Ilhéus.".

A chegada de novos moradores possibilitou a especulação imobiliária e o aumento no número de residências, desta forma, Ipiaú começou a sofrer transformações urbanas. Surgiram novas ruas, bairros, avenidas, obras de infraestrutura e saneamento, prédios escolares, postos de saúde, entre outros benefícios.

O processo de expansão urbana continuaria impondo transformações nas décadas seguintes. Na tabela 1, é possível identificar que o aumento da população não ocorreu de forma impactante; porém, do ano de 1980 a 2010 a população urbana cresceu consideravelmente em relação à população rural, consequentemente, há o avanço da malha urbana sobre áreas rurais.

Tabela 1: População total, rural e urbana do município de Ipiaú- BA (1980 a 2017)

\begin{tabular}{lccccc}
\hline População & $\begin{array}{r}\text { População } \\
(\mathbf{1 9 8 0})\end{array}$ & $\begin{array}{r}\text { População } \\
\mathbf{( 1 9 9 1 )}\end{array}$ & $\begin{array}{r}\text { População } \\
\mathbf{( 2 0 0 0 )}\end{array}$ & $\begin{array}{r}\text { População } \\
\mathbf{( 2 0 1 0 )}\end{array}$ & $\begin{array}{r}\text { População } \\
(\mathbf{2 0 1 7})\end{array}$ \\
\hline $\begin{array}{l}\text { População } \\
\text { total }\end{array}$ & 39.806 & 43.723 & 42.913 & 44.390 & 47.704 \\
\hline $\begin{array}{l}\text { População } \\
\text { urbana }\end{array}$ & 27.887 & 36.408 & 37.924 & 40.384 & Sem dados \\
\hline $\begin{array}{l}\text { População } \\
\text { rural }\end{array}$ & 11.919 & 7.315 & 4.989 & 4.006 & Sem dados \\
\hline
\end{tabular}

Fonte: PNUD, Ipea e FJP; IBGE (adaptado).

\section{Elementos culturais presentes na paisagem do Centro Urbano de Ipiaú}

Na figura 2, a seguir, é possível identificar os pontos em que estão localizados alguns dos elementos culturais que foram observados com a pesquisa na área central de Ipiaú. 
Figura 2: Localização da área comercial e signos presentes no centro urbano de Ipiaú-BA

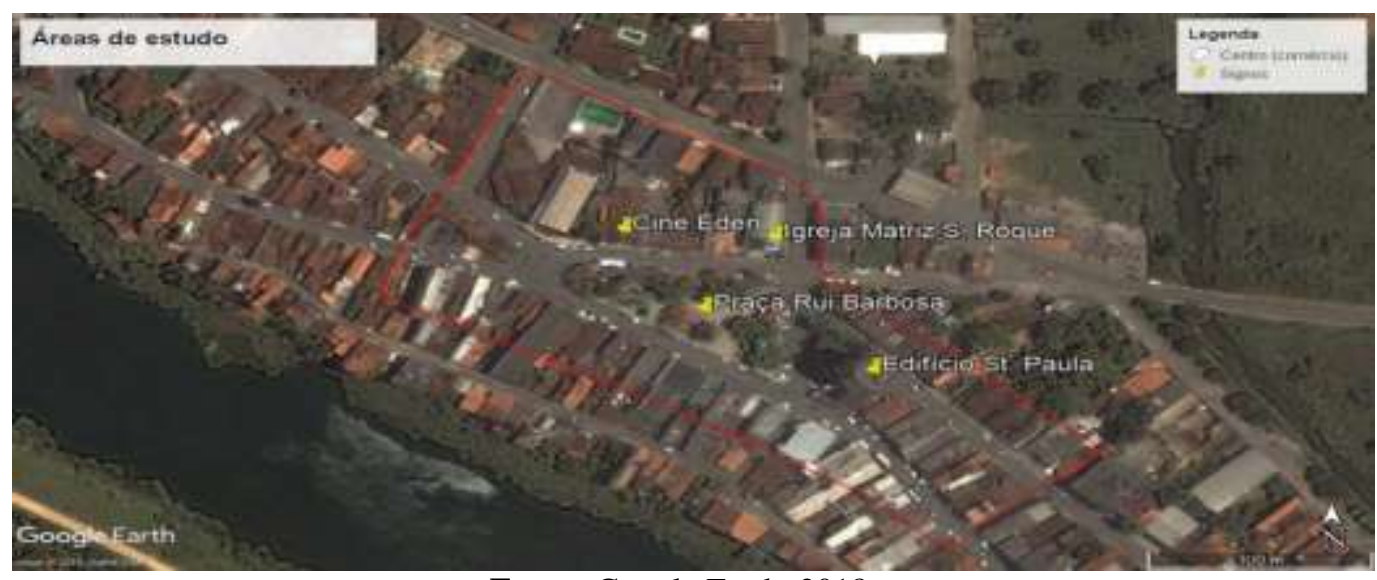

Fonte: Google Earth, 2018.

\section{A Praça Rui Barbosa}

A Praça Rui Barbosa (figura 3) é local onde se iniciou o processo do crescimento da cidade. A partir dali, deu-se início ao aglomerado urbano com a construção da primeira igreja, a Igreja Matriz de São Roque. Em matéria escrita para o site Giro, em Ipiaú, o jornalista e escritor José Américo Castro (2014) afirma que a partir dali, com o passar dos anos, a chegada de novas pessoas impulsionou sua expansão, e com a emancipação, a cidade começou a experimentar as transformações do seu espaço, com o surgimento de obras importantes de infraestrutura e saneamento. Na gestão do prefeito Euclides Teixeira Neto (1963-1967), foi o período em que a cidade mais sofreu transformações urbanas, que possibilitaram o recebimento do título de "Cidade Modelo da Bahia", concedido pelo Governo Federal. 
Figura 3: Praça Rui Barbosa em horário comercial, no sábado

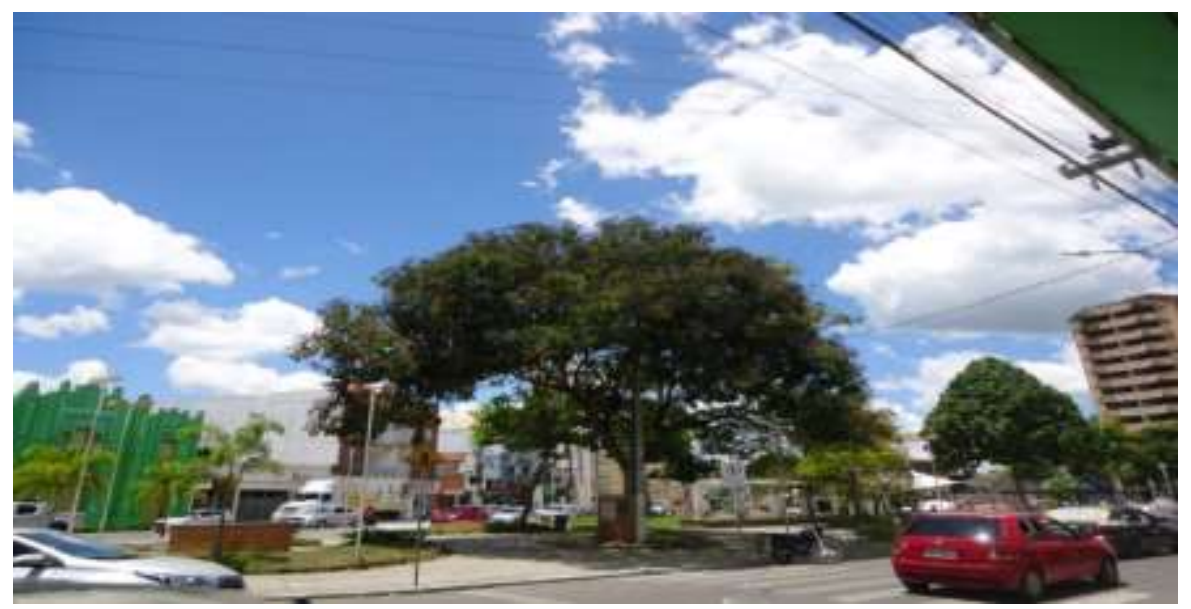

Fonte: Dados da pesquisa, 2018.

Por ser uma cidade pequena, as principais atividades requeridas pela população são concentradas no centro, não havendo processos de descentralização. A distribuição no espaço das formas e as funções existentes revelam sua organização intraurbana. Sendo assim, a praça Rui Barbosa exerce diversas funções: lazer, concentração comercial no seu entorno e lugar de realização de ações culturais. Em sua hinterlândia, há a concentração de variados tipos de comércio; do mais popular a boutiques, lojas de móveis e eletroeletrônicos, vestuário etc.; também há a presença de instituições bancárias privadas e públicas.

A Praça Rui Barbosa é local de conteúdo social, lazer e expressões culturais, palco de encontro de jovens e manifestações religiosas, além de ser o lugar central da cidade, onde em seus arredores há a presença de setores comerciais, de saúde, bancários e outros serviços. A praça é um signo que conduz a outros signos localizados nas suas proximidades, dando a esse espaço relevante significado sociocultural por ser local de concentração de atividades que fazem parte do cotidiano e da história da cidade. Também se faz presente como espaço onde esses elementos culturais, que são materiais, se fazem presentes como estímulo para relações imateriais que constroem e modificam o espaço constantemente.

Essas características fazem a Praça Rui Barbosa, área central do espaço urbano de Ipiaú, assumir uma dimensão simbólica para os indivíduos que a frequentam à procura do comércio, dos serviços ou mesmo para o lazer. Muitas vezes, eles não percebem que são agentes construtores e, ao mesmo tempo, integrantes daquele conjunto de formas materiais e não materiais que constituem a paisagem da área central de Ipiaú. Esses elementos assumem uma dimensão simbólica que abrange os diversos agentes sociais, etários etc.; portanto, pode ser considerado um espaço composto por uma associação distinta de formas materiais e não materiais, ou seja, formas culturais físicas e simbólicas. 


\section{O Cine Teatro Éden}

O Cine Teatro Éden (figura 4) chegou a Ipiaú por volta do ano de 1927, trazido pelo italiano José Miraglia. Ele abriu a primeira sala de cinema em um anexo de sua própria residência, que se localizava em uma das ruas que contornam a atual Praça Rui Barbosa, elemento este também de fundamental importância histórica e cultural do município.

Figura 4: Fachada do Prédio onde funcionou o antigo Cine Éden

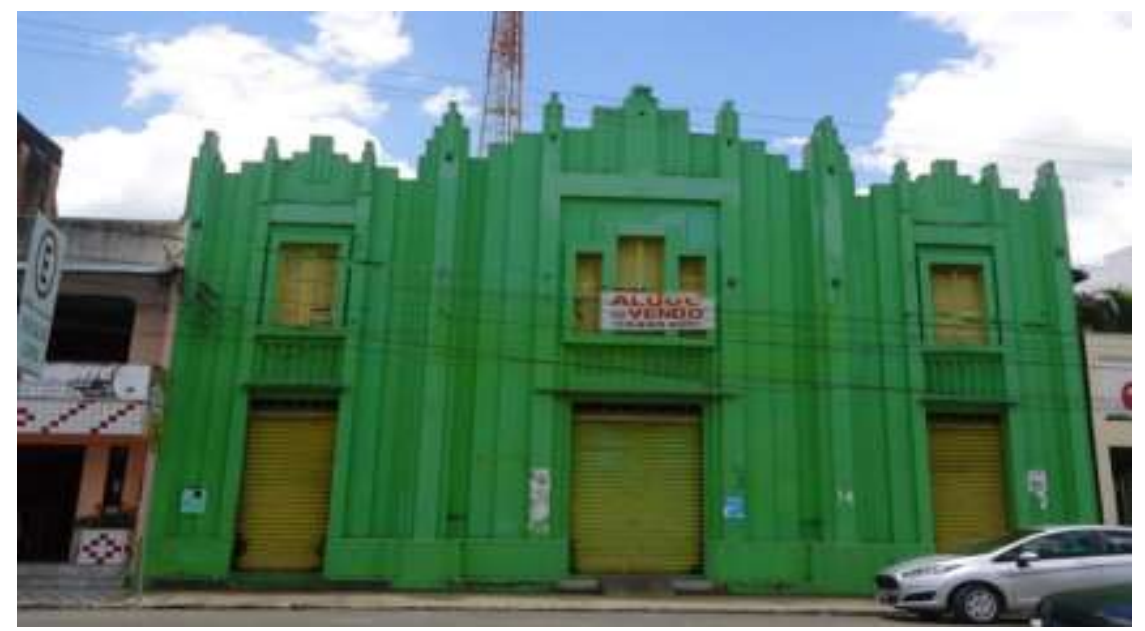

Fonte: Dados da pesquisa, 2018.

No início da cinematografia, os filmes não apresentavam narrativa sonora, sendo assim, a trilha sonora no Cine Éden era elaborada por um pianista e um narrador ao vivo durante a exibição do filme. Após a chegada do som ao cinema, foi construída uma nova sede do Cine Éden, onde sua estrutura física persiste até a atualidade. Sua fachada foi idealizada pelo próprio José Miraglia, que por ser italiano, trouxe referências da arquitetura italiana.

Após o fechamento do Cine Éden, sua fachada foi tombada no ano de 2001 e no local passou a funcionar uma loja de eletrodomésticos. Atualmente o local está sem uso, porém, há o interesse por parte da população em conjunto com o governo municipal pela revitalização deste espaço, que não funcionará somente como cinema, mas como centro de cultura, tornando-se espaço para exibições de cinema, arte, teatro e música. Ademais, o cinema foi fator importante na construção artística e cultural da cidade, além de fazer parte da memória e da identidade do lugar. 


\section{Igreja Matriz de São Roque}

A Igreja Matriz de São Roque (figura 5), foi fundada em 31 de maio de 1931, sendo a primeira igreja construída na localidade, foi o marco inicial do sítio urbano de Ipiaú. Na época, a igreja e o Estado ainda exerciam relação dual nas pequenas cidades do interior do país, estabelecendo a paz e a governabilidade no início dos povoamentos. Segundo Rosada (2014), a igreja era uma instituição que se aproximava dos cartórios, pois os padres, além de chefes religiosos, exerciam a função de escriturários, realizando os registros dos cidadãos e fiéis.

Figura 5: Igreja Católica construída ao padroeiro da cidade, São Roque

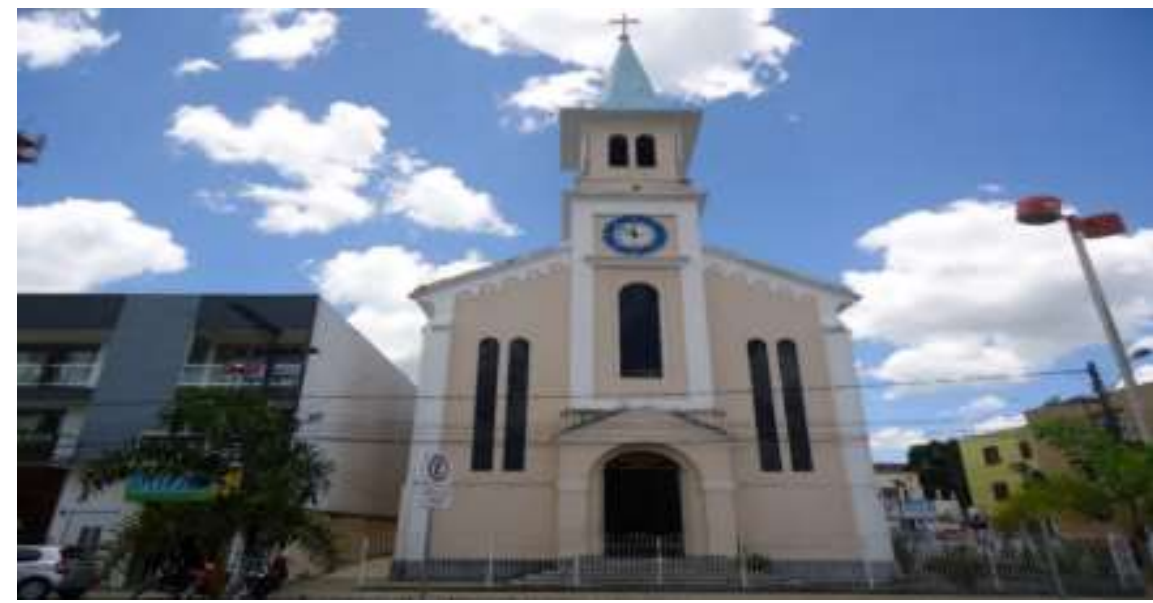

Fonte: Dados da pesquisa, 2018.

\section{Prédio Santa Paula}

O edifício Maison Vale dos Rios, mais conhecido popularmente como "Prédio Santa Paula" (figura 6), nome este com que ficou conhecido o empreendimento iniciado pela empresa de Itabuna (BA), Santa Paula, cujo projeto possui 16 apartamentos de classe alta, com vista panorâmica, tinha como objetivo proporcionar moradias para as famílias ricas e sediar os principais escritórios e empresas do município, sendo considerado na época o primeiro do gênero situado no interior do estado.

Na base do edifício está o Shopping Liberdade, a estrutura possui de 1 (um) andar, com galerias para lojas e espaço para bar e restaurante. Provavelmente, a intenção daqueles que executaram o projeto, seria o de promover exclusividade de acesso dos moradores do edifício às lojas, bares e restaurantes de padrão igualitário aos seus inquilinos. É possível perceber a tentativa de inclusão da cidade de Ipiaú no acelerado processo de urbanização que o país foi atingido na Ditadura Militar, no período chamado de "milagre econômico". 
Figura 6: Edifício Maison Vale dos Rios (Prédio Santa Paula)

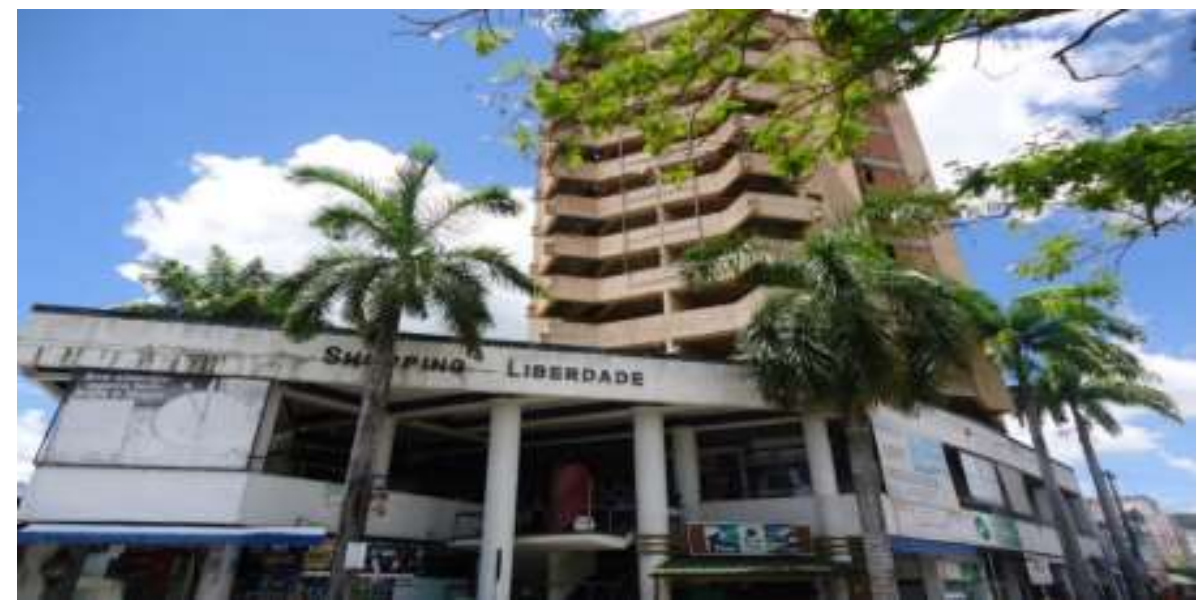

Fonte: Dados da pesquisa, 2018.

No final dos anos 1970 foi dado o primeiro e estagnado passo na tão sonhada verticalização da cidade, época em que era denominada como cidade modelo da Bahia por seu constante nível de crescimento e investimento em infraestruturas urbanas geradas pela riqueza que o cacau proporcionava naquela época. A tentativa de verticalização existente em Ipiaú diferencia-se das outras pequenas cidades da região; este elemento, segundo Corrêa (2005), está associado a processos de definição e distribuição das funções e formas no espaço, determinando áreas de valorização e especulação imobiliária.

Com menos de um ano de iniciação das obras, a crise se abateu sobre a principal atividade produtiva da região, causando a falência da construtora responsável e de seus patrocinadores, os produtores de cacau. Atualmente, a obra segue inacabada depois de quase 40 anos, sendo considerada por alguns, símbolo de empreendimentos que "não vão para frente".

A paisagem urbana do centro de Ipiaú possui heranças do passado que definem sua função enquanto centralidade urbana; Corrêa (2005, p.8) afirma que "o espaço urbano é um reflexo tanto de ações que se realizam no presente como também daquelas que se realizaram no passado e que deixaram suas marcas impressas nas formas espaciais do presente". Através do olhar do geógrafo, o edifício é símbolo, simultaneamente, de seletividade e de segregação espacial, impostas pelas culturas dominantes, produto de relações sociais que refletem a cultura hegemônica do momento histórico ainda no presente; este elemento material se torna signo da paisagem urbana de uma pequena cidade, paisagem esta que foi transformada de acordo com os interesses e necessidades de agentes hegemônicos da sociedade local. 
A divisão da sociedade em classes define diferentes posições sociais, que designam desiguais níveis de qualidade de vida, consciência da realidade e acesso à cultura. Desta forma, a cultura dominante irá legitimar a sua como realidade para todas as pessoas e definir os objetos e espaços que devem existir. O único prédio de grande porte da cidade foi uma tentativa de verticalização elaborada no auge da produção cacaueira e falida assim que a crise econômica atingiu a região. A forma permanece na paisagem sem exercer qualquer tipo de função social; reflete, de maneira material, o símbolo de um passado áureo na economia regional que define as relações sociais e culturais dominantes da época. Também revela a tentativa de crescimento urbano através da verticalização, tendência da urbanização brasileira a partir de meados do século XX.

\section{O Comércio da cidade de Ipiaú}

De acordo com os processos e formas espaciais da cidade, destaca-se o predomínio da área central sem a existência de áreas de descentralização e núcleos secundários. A área central estabelece conexões de fluxos, sejam de mercadorias, pessoas etc., e mantém uma articulação em escala regional e em outras escalas mais amplas, fora dos limites municipais.

No centro de Ipiaú (figura 7a), há a presença de setores comerciais, de saúde, bancários e outros serviços. Os diferentes fixos se localizam concentrados e levam ao processo de coesão, pois a área central da cidade exerce atividades e funções distintas que, apesar de algumas não manterem ligações entre si, são complementares, pois atraem os consumidores para o Centro, onde têm a possibilidade de escolha entre diversos produtos e preços, podendo mesmo induzir o consumidor a adquirir outros bens e serviços que, a princípio, não tinha intenção de comprar.

Figura 7(a): Comércios no centro de Ipiaú com destaque para o Prédio St. Paula

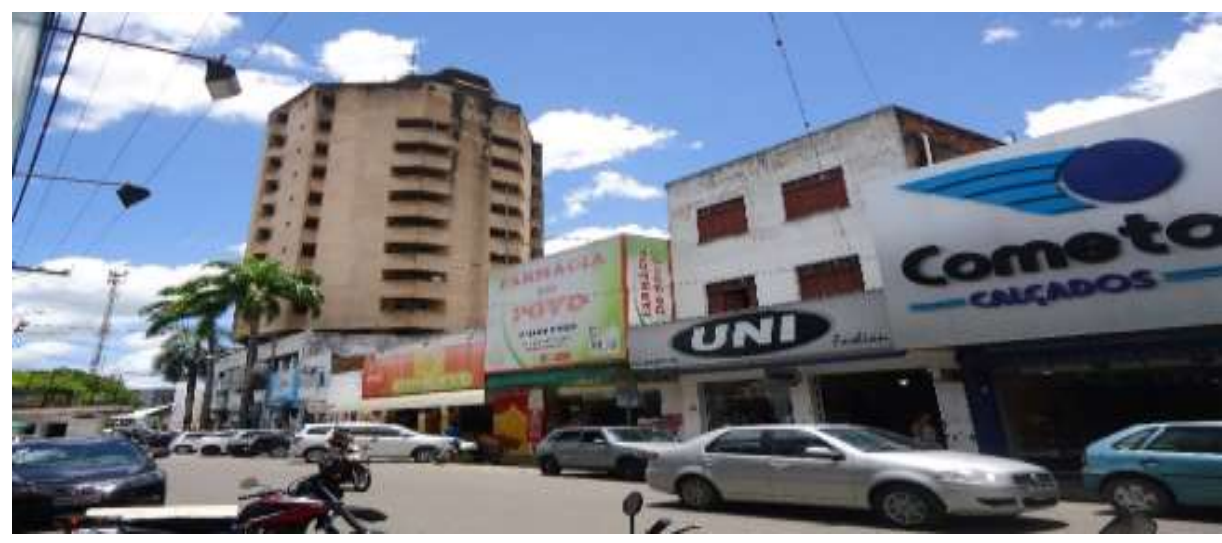

Fonte: Dados da pesquisa, 2018. 
A concentração de diferentes atividades (figura 7b) gera fluxos constantes de pessoas; seja a trabalho, passeio ou à procura de serviços e bens de consumo. A localização e a acessibilidade do centro de Ipiaú atraíram diversas atividades de comércio, escritórios e clínicas médicas voltadas para seus habitantes e moradores dos municípios da área imediata de influência. De acordo com Trindade (2011, p. 169):

Para a área central dessas pequenas cidades convergem os fluxos da zona rural, dos distritos e povoados, e mesmo das cidades circunvizinhas. Os estabelecimentos comerciais e de prestação de serviços atendem a uma demanda de consumidores locais que não dispõe de tempo ou de recursos para se deslocar até os centros regionais.

Figura 7(b): Estabelecimentos comerciais no centro de Ipiaú

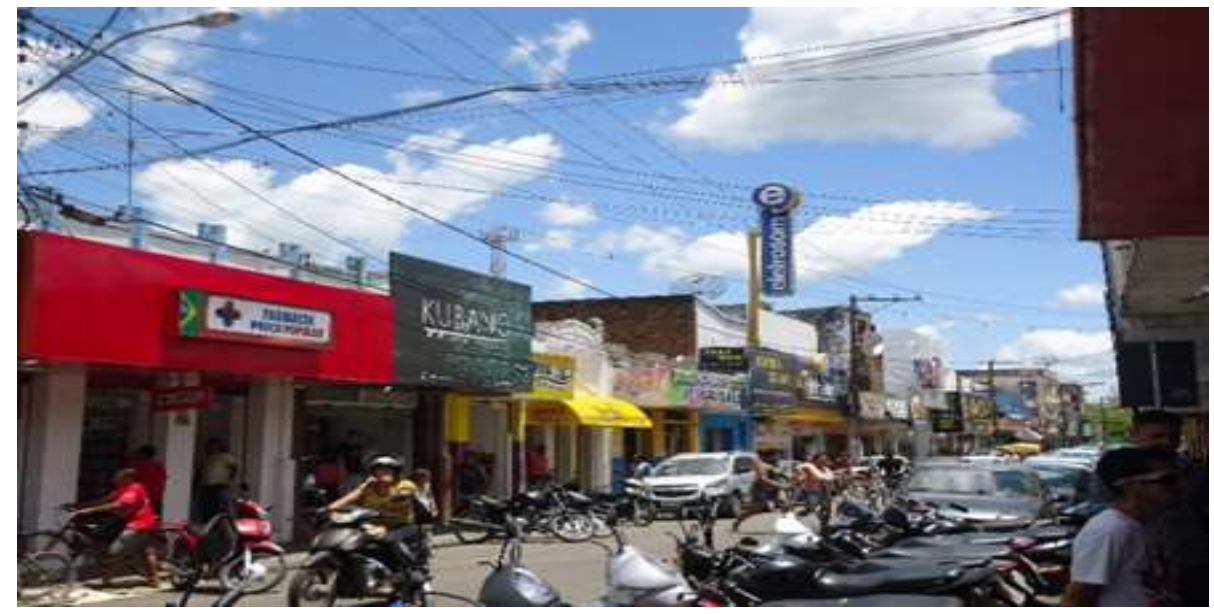

Fonte: Dados da pesquisa, 2018.

Os estabelecimentos presentes na área central são as lojas de vestuário e calçados, eletrodomésticos, farmácias, consultórios médicos, óticas, papelarias e lojas de produtos importados. Estas atividades se concentraram na área central da cidade fazendo com que o local se torne um centro de referência local na rede urbana regional para busca de tais serviços.

\section{CONSIDERAÇÕES FINAIS}

O sujeito social como parte integrante na produção do espaço cria funções e formas espaciais, guiado através da cultura que constitui as formas presentes na organização espacial, resultando na paisagem urbana das cidades. A análise do centro de Ipiaú aponta para a 
observação dos agentes modeladores de natureza social e histórica que definem os processos e formas espaciais do espaço urbano e sua paisagem, que nem sempre são notados. Dessa forma, é preciso perceber o potencial educativo dos espaços urbanos, e a escola, além de explorar as funções tradicionais de atividades sociais e econômicas da cidade, deve exercer o papel de uma escola que forma cidadãos ativos e que busca integrar os diferentes grupos sociais.

Nesse sentido, considerar os elementos culturais localizados no centro urbano de Ipiaú como referências de bens simbólicos da cidade, por serem lugares de uso frequente por pessoas de diferentes idades, condições socioeconômicas e distintos espaços da cidade, possibilita o encontro, a interação e o estabelecimento de sociabilidades que fortalecem os vínculos e a dimensão cultural do espaço. Portanto, utilizar-se das relações com o lugar do cotidiano dos alunos abre possibilidades para trabalhar de forma prática com diferentes conteúdos geográficos e interdisciplinares. É crucial que o aluno, como indivíduo que faz parte da composição e construção da sociedade, saiba reconhecer criticamente o espaço vivido em seu cotidiano. A observação da paisagem central da cidade de Ipiaú dá condição a percepção do meio e auxilia na construção e entendimento da composição socioespacial, contribuindo para o pensamento e ações críticas relacionadas ao meio ambiente e social em que se vive.

Além disso, o professor de Geografia, como profissional de uma área da educação que estimula o pensamento crítico, tem a seu alcance variadas possibilidades de dinamizar as suas aulas, estimulando a autonomia na produção de conhecimento dos alunos, a partir de vivências comuns à sua realidade, atrelado a isso, está a possibilidade de trabalhar em conjunto com profissionais de outras áreas do conhecimento, com aulas dinâmicas e interdisciplinares.

Apresentar os conceitos da Geografia de maneira tradicional em sala de aula pode não ser suficiente para a sua compreensão, pois, o ensino público posto convenientemente pelos governantes, não estimula a interpretação e reflexão, o aluno pode não assimilar os conceitos ligados à realidade espacial, mesmo que esta faça parte de seu cotidiano. A utilização da prática de campo em Geografia se torna essencial no momento em que o espaço geográfico é seu objeto de estudo, logo, não se limita apenas ao espaço escolar, que também é geográfico. Ao perceber os conceitos geográficos que estão expressos e materializados no espaço urbano central de Ipiaú, o professor poderá trabalhar de forma interdisciplinar, e, através dos signos existentes neste espaço, explanar diversas abordagens históricas, sociais e geográficas que 
levam ao entendimento dos processos que culminaram na atual configuração da paisagem urbana do lugar de estudo.

A perspectiva de análise da paisagem urbana sob o olhar da Geografia Cultural pode ajudar a reconhecer os potenciais e os problemas das questões locais, ajudando o aluno a atuar de maneira consciente em suas transformações, a interpretação das paisagens cotidianas envolve o pesquisador/aluno, que traz consigo uma carga cultural e social expressa na sua visão de mundo. A partir dessa abordagem, a escola pode ampliar seus espaços educativos, estabelecendo um diálogo com a sociedade local, considerando as práticas culturais e socioespaciais representadas na paisagem urbana. Espera-se com esta proposta metodológica, que o professor de Geografia possua meios para instruir o aluno a compreensão do mundo, a partir do estímulo à percepção de seu lugar, reconhecendo os processos que levaram a composição da sua realidade, assim como perceber-se como agente atuante no espaço.

Portanto, através da análise de signos da área central da cidade de Ipiaú, identificados como: o Cine Éden, a Igreja Matriz de S. Roque, o Edifício St. Paula, o comércio e a Praça Rui Barbosa. Dentre eles, a praça se destaca como o lugar onde esses elementos culturais simbólicos se concentram em seu entorno; o comércio como um todo, foi identificado como signo por estar concentrado na área central da cidade e contribuir para que Ipiaú seja considerada centro de referência local na rede urbana regional para busca de consumo e serviços; o antigo cinema possui herança cultural e histórica da cidade, sendo identificado como signo por simbolizar a memória cultural da cidade; o edifício Santa Paula foi identificado como signo por ser legado da cultura dominante construída pela lavoura cacaueira e, que após a crise, tornou-se símbolo do atraso.

Todos estes elementos atuam como signos que foram fixados na área central e que influenciam nas relações imateriais que constroem e modificam o espaço continuamente, o centro de Ipiaú se constitui de diferentes usos e formas, que definem essa área como principal local de ocorrência das principais atividades sociais da cidade.

Estes elementos físicos presentes na paisagem do centro da cidade de Ipiaú marcam a história do início do aglomerado que se tornaria a cidade de Ipiaú, além de concentrar ali aspectos relevantes de sua história econômica e política. Sendo assim, o centro de Ipiaú possui importância enquanto forma espacial, e por este motivo se torna essencial para os estudos de Geografia na educação básica do município.

Ao trabalhar novas práticas, o professor de forma interdisciplinar, poderá utilizar-se dos signos identificados na pesquisa para levar o aluno a compreensão em escala ampliada 
através do estímulo à percepção da sua realidade local; reconhecendo os processos históricos de produção do espaço urbano e as relações sociais que culminaram na configuração atual da área central de Ipiaú. Além disso, a memória e a cultura locais são resgatadas ao se direcionar o olhar para esse espaço do cotidiano dos alunos, um espaço que concentra as principais relações desenvolvidas no presente e no passado da cidade.

\section{REFERÊNCIAS}

CARLOS, A. F. A cidade. 4. ed. São Paulo: Contexto, 1999. 98 p.

O espaço urbano: novos escritos sobre a cidade. São Paulo: Contexto, 2004. 154 p.

CASTRO, J. A. Um giro na evolução histórica de Ipiaú. Giro em Ipiaú, jul. 2014. Disponível em: $\quad<$ http://www.giroemipiau1.com.br/2014/07/um-giro-na-evolucao-historica-deipiau.html>. Acesso em: 12 out. 2017.

CHAGAS, A. T. R. O questionário na pesquisa científica. São Paulo: FECAP, 2000. V. 1. Disponível em: <http://www.fecap.br/adm_online/art11/anival.htm>. Acesso em: 25 jul. 2017.

CORRÊA, R. L. O espaço urbano. 4. ed. São Paulo: Ática, 2005. 94 p.

CORRÊA, R. L.; ROSENDAHL, Z. (Orgs.). Paisagem, tempo e cultura. 2. ed. Rio de Janeiro: EdUERJ, 1998. 124 p.

INSTITUTO BRASILEIRO DE GEOGRAFIA E ESTATÍSTICA-IBGE. Cidades, 2008. Disponível em: <http://cod.ibge.gov.br/2W58C>. Acesso em: 30 nov. 2017.

Histórico do município, 2008. Disponível em: <http://cod.ibge.gov.br/2WD03〉. Acesso em: 30 nov. 2017.

Sinopse por setores, 2016. Disponível em: <http://www.censo2010.ibge.gov.br/sinopseporsetores/?nivel=st>. Acesso em 06 de out. 2017.

INSTITUTO DE PESQUISA ECONÔMICA APLICADA (IPEA). Caracterização e tendências da rede urbana do Brasil: desenvolvimento regional e estruturação da rede urbana. IPEA, IBGE, UNICAMP/IE/NESUR. Brasília: IPEA, 2001.v.3; 127 p.

LATINI, K. M.; ARAÚJO, A. F. A importância do trabalho de campo no planejamento curricular da Geografia para a educação básica: um exemplo das escolas do município de Nova Friburgo. In: ENCONTRO NACIONAL DE PRÁTICA DE ENSINO EM GEOGRAFIA, 10. 2009, Porto Alegre, RS. Anais...Porto Alegre, RS: [s. n.], set. 2009. Não paginado.

LUCHIARI, M. T. D. P. A (re)significação da paisagem. In: ROSENDAHL, Z.; CORRÊA, R. L (Org.). Paisagem, imaginário e espaço. Rio de Janeiro: EdUERJ, 2001. p. 9-28. 228 p. 
MOTTA, D. M. da; AJARA, C. Configuração da rede urbana do Brasil. Revista Paranaense de Desenvolvimento, Curitiba, n. 100, jan./jun., p. 7-25, 2001. Disponível em: <http://www.ipardes.gov.br/pdf/revista_PR/100/diana.pdf >. Acesso em: 2 fev. 2017

ROCHA, L. B. O centro da cidade de Itabuna: trajetória, signos e significados. Ilhéus, BA: Editus, 2003. 190 p.

ROMMEL, C. Ipiaú: Edifício Santa Paula, quase quarenta anos de atraso. Disponível em: $<$ http://ipiauonline.com.br/ipiau-edificio-santa-paula-quase-quarenta-anos-de-atraso/>. Acesso em: 25 mar. 2018.

ROSADA, M. O plano sem traçado: a Igreja na lógica urbanística portuguesa de criação das vilas coloniais. In: PEIXOTO, E. R.; DERNTL, M. F.; PALAZZO, P. P.; TREVISAN, R. (Orgs.) Tempos e escalas da cidade e do urbanismo, 2014, Brasília, DF. Anais do XIII Seminário de História da Cidade e do Urbanismo. Brasília, DF: Universidade BrasíliaFaculdade de Arquitetura e Urbanismo, 2014.Disponível em: <http://www.shcu2014.com.br/content/plano-tracado-igreja-na-logica-urbanisticaportuguesa-criacao-das-vilas-coloniais>. Acesso em: 01 maio 2018.

TRINDADE, G. A. Aplicação dos conceitos geográficos no ensino fundamental e médio. In: TRINDADE, G. A. et al. Geografia e ensino: dimensões teóricas e práticas para a sala de aula. Ilhéus, BA: Editus, 2017. p. 26-36.

Aglomeração Itabuna-Ilhéus: cidade, região e rede urbana. 361 p. Tese (Doutorado em Geografia) - Universidade Federal de Sergipe, São Cristóvão, SE. 2011.

TURRA NETO, N. Geografia Cultural, juventudes e ensino de Geografia: articulações possíveis. Revista Formação, Presidente Prudente -SP, v. 1, p. 38-56, 2013. 